\title{
New Course Development in Electronic Products and Systems Cost Analysis
}

\author{
Peter Sandborn \\ CALCE Electronic Products and Systems Center \\ University of Maryland, College Park, MD 20742 \\ sandborn@calce.umd.edu \\ David T. Allen and Cynthia F. Murphy \\ Center for Energy and Environmental Resources \\ University of Texas, Austin, TX 78758
}

\begin{abstract}
This paper presents a new graduate level cost analysis course that has been taught in the Mechanical Engineering Department at the University of Maryland. The objective of this course is to provide students with an in-depth understanding of the process of predicting the cost of systems. Elements of traditional engineering economics are melded with manufacturing process modeling, life cycle cost management concepts, and selected concepts from environmental life cycle cost assessment to form a practical foundation for predicting the real cost of electronic products.

Various manufacturing cost analysis methods are included in the course: process-flow, parametric, cost-ofownership, and activity based costing. The effects of learning curves, data uncertainty, test and rework processes, and defects are considered in conjunction with these methodologies. In addition to manufacturing processes, the product life cycle costs associated with design, procurement, manufacturing waste, sustainment, and end-of-life are also addressed. This course uses real life design scenarios from integrated circuit fabrication, electronic systems assembly, substrate fabrication, and testing at various levels.

As a next step in the development of these educational materials, we propose to expand the involvement of industry in the course and create a set of web-based modules for use in this course, and as supplements to other courses. In addition, we will expand the elements the course addressing environmental costs, particularly the concepts of environmental life-cycle assessment (LCA) and design for environment (DFE). Simplified methodologies and metrics that demonstrate the economic impact environmental issues will be incorporated.
\end{abstract}

\section{Introduction}

Whether an electronic product is targeted for a lowvolume avionics application, or the shelves of the local grocery store, its cost is important. Ten years ago engineers involved in the design of electronic systems did not concern themselves with the cost effectiveness of their design decisions; that was someone else's job. Today the world is different. Every engineer in the design process for an electronic product is also tasked with understanding the economic tradeoffs associated with their decisions. More recently, the environmental impact of a product during both the manufacturing and disposition phases of its life has gained increasing importance to the designer. While, the majority of the interest has been in Europe and Japan, US suppliers are finding that they must also begin considering environmental aspects of a product in order to remain globally competitive.

In the 1990s many universities introduced courses in electronic packaging, and a few universities developed course streams and entire curriculums for the electronic packaging engineer. These offerings include general introductions to packaging technology, thermal analysis, mechanical analysis, materials issues, reliability, electrical analysis, manufacturing and assembly, and a range of topical courses focused on specific technologies (e.g., multichip modules, plastic packaging, etc.). What these course offerings do not include is an organized treatment of the manufacturing or life cycle cost impacts associated with electronic packaging. In fact, with few exceptions the current course offerings in electronic packaging do not even mention the analysis of costs (manufacturing or otherwise) associated with the topics treated or the technological solutions considered. There is also no consideration of environmental aspects such as waste minimization in the manufacturing environment (an absolutely critical economic element in printed wiring board manufacture) and end-of-life concerns (a significant cost driver for products subject to takeback legislation in Europe).

This paper presents a new graduate level cost analysis course that has been taught in the Mechanical Engineering Department at the University of Maryland. Other cost analysis courses are taught within the engineering departments of most universities including engineering economics and life cycle cost analysis. Both of these areas are important, but neither provides the cost analysis background that is needed by design engineers and neither have an electronic systems focus, let alone electronic packaging.

Engineering economics treats the analysis of the economic effects of engineering decisions and is often identified with capital allocation problems. Engineering economics provides a rigorous methodology for comparing investment or disinvestment alternatives. Alternatively, this course focuses on the detailed cost modeling necessary to supply engineering economic analyses with the inputs required for investment decisions.

Life cycle cost management (LCC) courses traditionally focus on "program" level cost analyses broadly used in the defense community, i.e., LCC provides the background necessary to manage costs associated with large government 
system contracts. LCC's view of the world is that while manufacturing operations (fabrication, assembly, and test) are important, life cycle issues (qualification, maintenance, upgrade, obsolescence, design, reliability, acquisition) represent the thrust of the analysis - and this is appropriate for complex systems with long field lives like aircraft and tanks. LCC is also appropriate for the electronics industry in the area of manufacturing equipment and facilities. In fact, the widely accepted cost-of-ownership model is a permutation of LCC. However, LCC has not found wide acceptance for high-volume, time-to-market driven commercial products. Most commercial products have different cost drivers than defense systems and equipment; commercial product cost analysis is driven by detailed analysis of fabrication/assembly/test costs and less by life cycle costs.

A third distinct set of elements that are mixed into this course are key concepts from environmental life cycle assessment. With the advent of more stringent environmental regulations and product takeback laws, manufacturers of many products are being forced to consider the waste streams associated with their products and contend with the possibility that products will be returned to the manufacturer at the end of the product's primary life. An additional concern is that products may be improperly disposed of resulting in potential long-term liability issues. The costs associated with waste stream management are especially important in printed wiring board fabrication where disposal costs of process materials may represent $10 \%$ or more of the cost of the board. In Europe, consideration of the product end-of-life (EOL) scenarios during product design (e.g., resale, remanufacturing, recycling, disposal, and refurbishing) is becoming increasingly critical for most electronic products, including televisions, computers, and small appliances.

The objective of this course is to focus on the detailed fabrication/assembly/test cost analysis that the commercial world uses and mix in key concepts from LCC and environmental cost assessment that the commercial world may not be considering today but should (Figure 1).

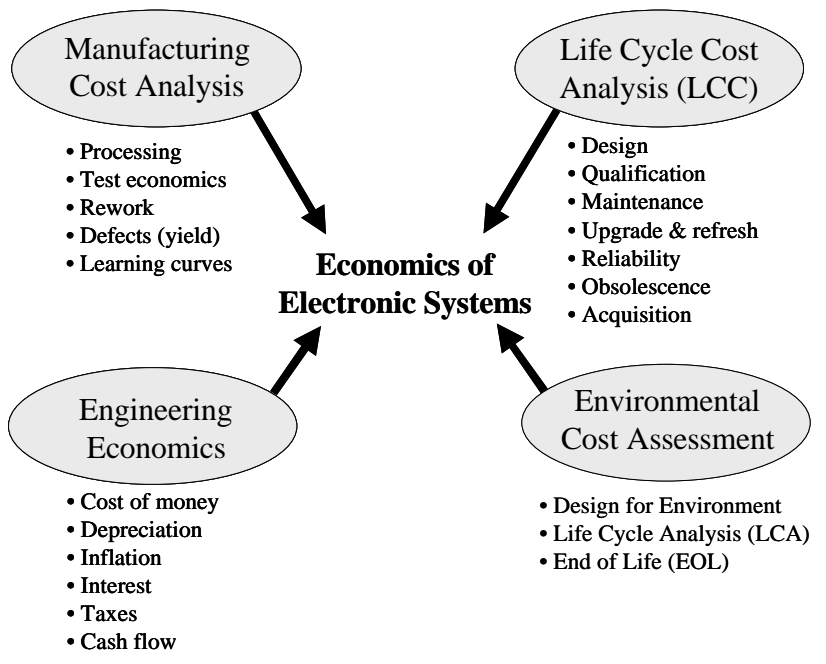

Figure 1. Key concepts forming the foundation for the electronic products and systems cost analysis course.
At this time, this cost analysis course has been taught as a graduate level, one semester course at the University of Maryland and as a 3 day short-course for specific industrial partners within the Computer Aided Life Cycle Engineering (CALCE) Consortium at the University of Maryland. An outline of the current course is shown in Table 1.

Table 1. Outline of current electronic products and systems cost analysis course

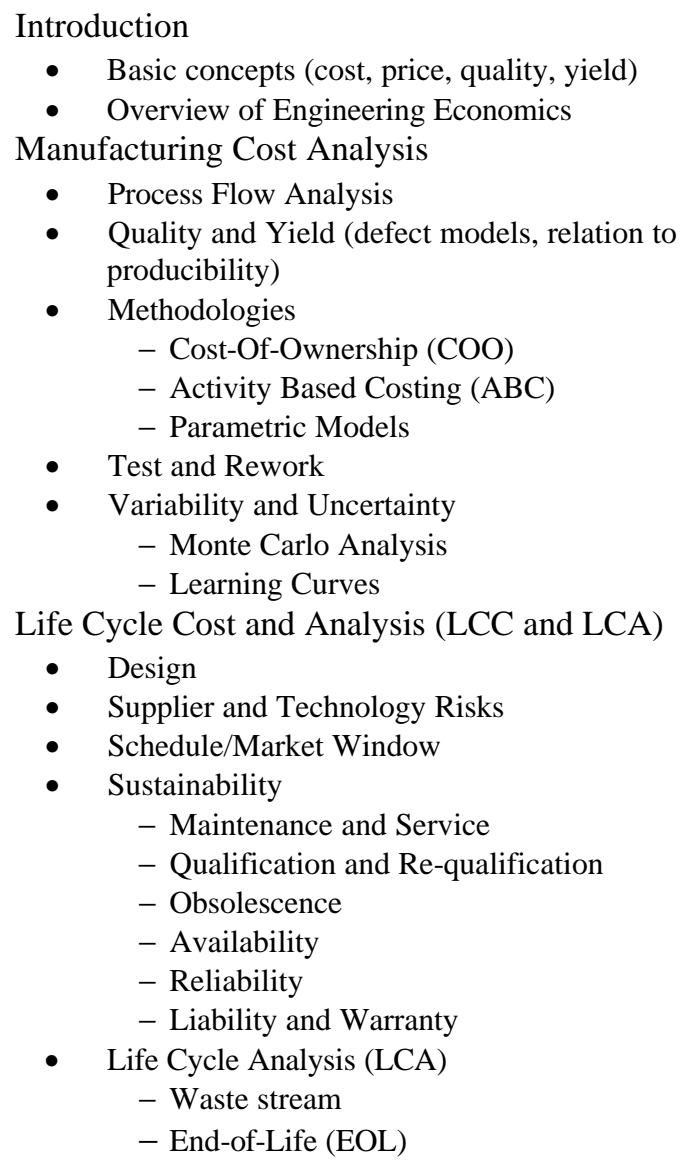

We propose to expand this course to include a series of web-based modules that can be used as supplements within this and other courses associated with electronic systems. In addition, the environmental cost portions of the existing course will be expanded upon by tying environmental metrics to the existing cost modeling methodologies.

\section{Proposed Cost Analysis Modules}

Recently, a multimedia module-based paradigm for packaging education was introduced [1]. The multimedia modules are intended to be web-based and hosted by a central organization such as the IEEE. The modules would be designed in such a way as to make packaging education materials available to a large number of universities and industrial workers worldwide, as well as others interested in education, and to provide a platform that facilitates quick and easy contribution of additional materials.

The educational modules developed to date, or that are currently being developed, cover basic electronic packaging, 
thermal analysis, electrical analysis, and various aspects of package and board manufacturing. Analysis of the cost impacts of packaging assemblies, chips, and substrates is not addressed either in the modules developed to date or in packaging education curricula. However, for many (most) systems, cost may be the most important single attribute, and definitely the most visible attribute to corporate management. In addition using the cost-modeling paradigm for environmental analysis is the only way that corporate management understands the quantitative effects of responsible and proactive environmental activities.

Using elements of the current course (Table 1) with proposed content modifications in the area of environmental life cycle assessment, we will fill this hole by developing a coordinated set of modules that treat issues relevant to the economics of electronic systems.

The proposed modules can be used together within the semester length upper-division or graduate course outlined in Table 1, or a subset may be chosen for 2-3 day short courses. An additional important attribute is that the proposed modules are designed so that individual modules and portions of modules can be used within other packaging courses in curricula that can not support an entire course focused on cost analysis.

In order for the modules to have the broadest possible applicability as course material, we have defined the following set of six core areas for initial module development:

Process Flow Analysis Module - The process flow analysis module introduces manufacturing processes as a sequence of process steps. Each process step is defined by a set of inputs received from the previous step in the sequence, and a corresponding set of outputs (matching the inputs) passed to the next step in the sequence. This module focuses on process step attributes that can be directly linked to computing costs associated with the process step, i.e., labor, material, tooling, and equipment/facilities content. Concepts of throughput, operator utilization, process time, depreciation, and piece format (number-up on wafers or panels) will be addressed.

The process flow development will be supplemented with demonstrations and discussion problems that can be solved using spreadsheets and the introduction of more sophisticated Java-based process construction and modeling software from the University of Maryland.

Quality and Yield Module - Various types of defects are introduced along with metrics that can be used to characterize them. The concept of yield is introduced and several yield relations are derived assuming various spatial defect distributions. With yield relations in hand, the discussion turns to how defects and yields can be accurately accumulated through a process.

With a basic understanding of yield, defects are introduced into sample process flows and yielded cost (cost divided by yield) is explored. Students learn how to use yielded cost as the basis for tradeoff analysis between manufacturing alternatives. Finally, process capability indices are related to yield and correlations between $C_{p}, C_{p k}$ and yield are explored.

Several auxiliary discussion problems are posed that students may explore, including:

- Hot lots - lots in wafer fabrication facilities, or board assembly facilities that are accelerated through the process bypassing other product builds.

- Yield learning - defect related yield changes over time in production processes.

- Yield with redundancy - modeling yielded cost for systems that contain redundancy.

Test Economics Module - This module discusses the relationship between defects and faults, develops the concept of fault coverage and relates it to the yield and cost after the execution of a test operation.

The module begins by posing the basic questions associated with selecting or designing a test: 1) when should I test (at what point(s) in the manufacturing process)? and 2) how much testing should I do (i.e., how thorough a test should I pay for)? Discussion begins with definitions and examples of defects and faults. Defect and fault spectrums are introduced and students derive conversion matrices to map between them. The defect/fault spectrums are used to introduce the concept of fault coverage. Students are allowed to make intuitive use of fault coverage to derive the outgoing yield, scrap fraction, and cost associated with test steps in a fabrication process. The derivation of the attributes of a test step is performed with a concise interpretation of fault coverage using a hypergeometric distribution to properly represent a system that is sampled without replacement.

Armed with a formulation of the yield, cost, and scrap levels resulting from test steps, students develop solutions to a series of test modeling scenarios from electronic system fabrication and assembly including:

- Test steps, just like other process steps, introduce defects into products. Show how the equations for Cost $\mathrm{Cut}_{\text {, }}$, Yield $_{\text {out }}$ and Scrap Fraction are modified by Yield test $_{\text {(the }}$ yield of the test step). Note, Cost ${ }_{\text {out }}$, Yield ${ }_{\text {out }}$ and Scrap Fraction are modified differently depending on your assumptions about when the defects introduced by the test step occur.

- Test operations are most commonly characterized by their fault coverage and correspondingly, the number of test escapes they produce (i.e., the number of defective parts they do not catch). In some test operations, a troublesome problem is the number of good (nondefective) parts that erroneously test bad. Derive a test step that includes a "false positive fraction" in addition to fault coverage. The false positive fraction is the fraction of good parts that the test step will erroneously determine are bad and send to scrap.

- A PWB manufacturer knows the yield of printed wiring boards after fabrication. Given board and panel sizes 
along with the defect levels contributed to the panel during the board fabrication process, derive the overall fault coverage realized by the testing process.

- Multiple test operations (each detecting different types of faults) are executed in series. Determine how to accumulate scrap through these test steps.

- Packaged chips can be tested prior to their assembly onto boards, however, bare die can not be easily tested prior to assembly. The family of issues raised by the availability (or lack of availability) of tested bare die is called Known Good Die. Assume that a Multichip Module (MCM) is being manufactured with a set of identical bare die on it. Using a relation that correlates fault coverage to test cost, what yield of die should be purchased for the module?

Wafer probing, test throughput, test pattern generation, and design for test cost tradeoffs are also briefly covered within the test economics modules. Advanced students may apply Monte Carlo techniques to determining the distribution of faults introduced into chips and assemblies and thereby obtain outgoing yield and cost distribution functions from test steps.

Life Cycle Concepts Module - The life cycle overview module will introduce the student to the concept of life cycle for a product. Within the life cycle context the product may be evaluated as a function of cost, materials inventory, and/or environmental impact. Typically these evaluations must be done as sensitivity and trade-off analyses, as there is typically not a single correct answer.

The life cycle of a product, as addressed in this presentation, considers 5 stages within the life cycle: design, procurement, manufacturing, sustainment (i.e., product use), and end-of-life.

- Design is assumed to take place as a concurrent engineering activity and as such has many "Design for $X$ " considerations. The two most critical areas within the context of this course are design for manufacturing (DFM) and design for environment (DFE). While no modules specific to these areas will be developed at this time, an introduction will be made within the Life Cycle Module and form the basis for potential future modules.

- Procurement addresses supplier and technology risks as well as component and material selection for cost and environmental considerations

- Manufacturing will be covered briefly as it is addressed in detail in the Process Flow Analysis Module, the Quality and Yield Module, and the Test Economics Module. Emphasis will be placed on understanding how manufacturing relates to the other stages of the product life cycle. Waste inventory, waste minimization, and disposition costs will also be addressed in association with process flow models.

- The sustainment stage in the life cycle is addressed in detail in the Product Sustainment Module, so discussion within this module will be limited. Emphasis will be placed on how decisions made during other phases of the life cycle affect this stage. For example, design or manufacturing decisions that reduce immediate costs may result in compromised product reliability and ultimately create higher costs (direct and indirect) for the manufacturer.

- End-of-life options for a product, its components, and materials include reuse (such as through by-product synergy), remanufacture, recycling, and disposition. The factors that must be considered in optimizing product end-of-life will be discussed. Modeling of the remanufacturing option is covered in detail in the endof-life module.

Product Sustainment Module - This module focuses on the costs associated with sustaining an electronic product throughout its field use. Several key sustainment topics are treated including:

- Maintenance - scheduled and un-scheduled maintenance operations are modeled and the quantity of spares needed to support field operations is computed. Students explore maintenance problems using links to software from PRICE Systems.

- Reliability - The economic impact of component failure rates is introduced. The interpretation of Mean Time Between Failure (MTBF) in a cost-modeling environment is explored and alternative metrics for characterizing systems, such as Maintenance and Failure Free Operating Periods (MFOP and FFOP) are introduced and related to the sustainment costs of electronic systems.

- Energy and Material Consumption. The cost of operation may be tied to energy and material consumption (including water use). These factors also affect the environmental impact of a product.

- Obsolescence - Concepts of technology and part obsolescence are introduced. Obsolescence mitigation techniques are explored with an eye to their economic pros and cons. Student use Java-based software from the University of Maryland to model the costs of electronic assemblies where the parts are constrained by windows of obsolescence and time-to-failure data.

End-of-Life (EOL) Module - A product's end-of-life is becoming increasingly important for design engineers. Takeback legislation in Europe and Japan is placing greater disposition and material content responsibilities on the Original Equipment Manufacturer (OEM) and its suppliers. The increasing trend in leased equipment also results in more equipment being returned to the OEM, where the most attractive option is to salvage usable components and performed closed loop recycling on the bulk of the materials. Finally, the concept of product stewardship within many corporations is resulting in increased awareness of environmental impact along the supply chain. Consequently, a component designer may find it necessary to consider the end-of-life of a customer's product. 
The end-of-life module discusses the pros and cons of reusing selected portions of a product within new products. The module formulates the necessary relations (based on manufacturing, test, and disassembly concepts already addressed in the course) for quantitatively assessing the cost and material waste of various salvage options for electronic assemblies. The relations derived in this module are implemented within a Java software tool shown in Figure 2, [2]. Students can use the tool to demonstrate the important concepts introduced in the module and solve homework problems.

This tool has particularly applicability for leased equipment (e.g., copiers and computers), for products with very tight closed-loop life-cycles (such as single use cameras), and for products that have the potential for re-use of costly components.

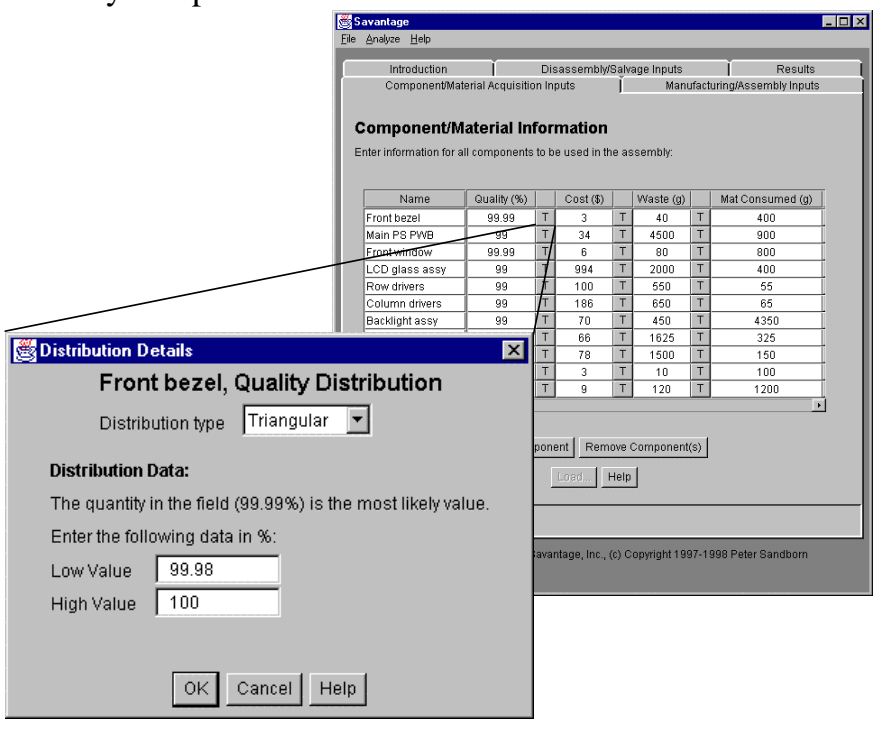

Figure 2. Example of Java software tool interface for inputting component characteristics for the study of salvage tradeoffs in the design of an electronic system.

The software tool has the additional appeal of being fully Monte Carlo capable, i.e., every input can be optionally represented by one of several probability distributions. Students can vary the number of Monte Carlo samples and observe the resulting histograms for cost, yield, and waste volume.

\section{Module Use as Supplemental Course Material}

Because existing electronic packaging courses currently taught in universities have little or no treatment of manufacturing or life cycle costs, and cost constraints pervade nearly every facet system design, it is uniquely important that the modules developed in this course can be used individually or in groups to provide valuable supplemental instruction opportunities in courses where cost analysis has not previously been addressed. The modules developed within this effort will be applicable to introductory packaging technology, manufacturing, test, and "capstone" design courses.
The modules are also designed for insertion into more broadly based engineering or business curriculums, such as in a design for environment or industrial ecology course, where it is important for the student to understand the relationship between the different phases of a product's life and the interdependencies of cost and environmental impact.

The module format for this course allows abbreviated treatments of cost analysis to be easily selected and used within short courses or as part of other electronic packaging courses.

\section{Linking the Modules to the State of the Art}

One unique attribute of this course is its strong link to industry. Table 2 shows companies that have participated in, or been approached to participate in the construction and presentation of the course offered at the University of Maryland.

Table 2. Commercial providers of cost analysis software and services to the electronics industry that have either participated in, or been approached to participate in this course

\begin{tabular}{|l|l|}
\hline Activity Based Costing & $\begin{array}{l}\text { ABC for all types of } \\
\text { electronics companies }\end{array}$ \\
\hline Wright, Williams and Kelley & $\begin{array}{l}\text { COO for integrated circuit } \\
\text { fabrication and board assembly }\end{array}$ \\
\hline Nu Thena Systems (Savantage) & $\begin{array}{l}\text { Process flow modeling of sub- } \\
\text { strate fab. and board assembly }\end{array}$ \\
\hline PRICE Systems & $\begin{array}{l}\text { Parametric life cycle cost } \\
\text { modeling }\end{array}$ \\
\hline Bosonics & $\begin{array}{l}\text { COO for MEMS and electro- } \\
\text { optical systems }\end{array}$ \\
\hline
\end{tabular}

In developing the proposed course we plan to expand the list in Table 2 to include a distributor of LCA (Life Cycle Assessment) and/or DFE (Design For Environment) software as well. These industry partners provide guest lecturers, and software tools for use in course homework problems and projects. Students gain valuable and relevant experience by using state-of-the-art tools, through exposure to real industry problems, and by having the opportunity to discuss cuttingedge modeling challenges faced in the cost modeling and environmental analysis community.

Industry involvement will be expanded with the proposed web-based modules by having industry representatives review the modules and prepare web-based tutorials involving their software tools that the students can use within the modules. We also plan to solicit design problems and critiques of student solutions to the design problems from industry.

\section{Proposed Development}

Table 3 shows the status of the course development. During a one-year period, 6 internet-based modules will be developed in the areas indicated in Table 3 and discussed in the last section.

The modules developed will include a mixture of lecture materials (in written and video format), case studies, on-line 
computational tools, bibliographies, links, and discussion/homework problems.

\section{Dissemination and Assessment of the Modules}

The materials to be developed in this effort will be immediately implemented in courses taught at the University of Maryland and The University of Texas (see Table 3). At the University of Maryland, the first use of the materials will be in an introductory electronic packaging course that all incoming graduate students associated with the CALCE Center are required to take (Fall 2000). At the University of Texas, the modules will be used in a Design for Environment course taught to upper-level undergraduate and graduate students through the Chemical Engineering Department. It is also anticipated that a portion of these modules may be used to teach an interdisciplinary course offering taught through a graduate school business program. All of these course insertions will be observed and student/instructor feedback collected to assess the effectiveness and relevancy of the test modules. The feedback will be used to iteratively make refinements in the course.

Table 3: Web-based module development plan

\begin{tabular}{|l|l|l|}
\hline Module & Developer & $\begin{array}{l}\text { Course(s) where the module will } \\
\text { be used for the first time* }\end{array}$ \\
\hline $\begin{array}{l}\text { Process } \\
\text { Analysis }\end{array}$ & $\begin{array}{l}\text { University } \\
\text { of Maryland }\end{array}$ & $\begin{array}{l}\text { Hardware Design for Information } \\
\text { and Computing Systems } \\
\text { (UMD - Fall 2000) } \\
\text { High-Density Interconnects and } \\
\text { Assemblies } \\
\text { (UMD - Spring 2001) }\end{array}$ \\
\hline $\begin{array}{l}\text { Quality and } \\
\text { Yield }\end{array}$ & $\begin{array}{l}\text { University } \\
\text { of Maryland }\end{array}$ & $\begin{array}{l}\text { Hardware Design for Information } \\
\text { and Computing Systems (UMD - } \\
\text { Fall 2000) } \\
\text { High-Density Interconnects and } \\
\text { Assemblies } \\
\text { (UMD - Spring 2001) }\end{array}$ \\
\hline $\begin{array}{l}\text { Test } \\
\text { Economics }\end{array}$ & $\begin{array}{l}\text { University } \\
\text { of Maryland }\end{array}$ & $\begin{array}{l}\text { Advanced Packaging: MEMS, } \\
\text { sensors, 3-D, MCMs } \\
\text { (UMD - Spring 2002) }\end{array}$ \\
\hline $\begin{array}{l}\text { Life Cycle } \\
\text { Concepts }\end{array}$ & $\begin{array}{l}\text { University } \\
\text { of Texas }\end{array}$ & $\begin{array}{l}\text { Design for Environment } \\
\text { (UT - Fall 2000) } \\
\text { Hardware Design for Information } \\
\text { and Computing Systems } \\
\text { (UMD - Fall 2000) }\end{array}$ \\
\hline $\begin{array}{l}\text { Product } \\
\text { Sustainment }\end{array}$ & $\begin{array}{l}\text { University } \\
\text { of Maryland }\end{array}$ & $\begin{array}{l}\text { Microelectronic Components } \\
\text { Engineering graduate course } \\
\text { (UMD - Fall 2000) }\end{array}$ \\
\hline of Texas & $\begin{array}{l}\text { Design for Environment } \\
\text { (UT - Fall 2000) }\end{array}$ \\
\hline All & & University \\
\hline
\end{tabular}

*All dates are tentative depending on actual dates of course offerings.

While most of the feedback obtained through this effort will measure the effectiveness of the asynchronous use of web-based modules (as supplemental information to existing courses), one of the modules developed will also be used to explore the practicality of synchronous learning. Using the experience gained in a previous effort at the University of Maryland [3], the Life Cycle Concepts module will be taught simultaneously at the University of Texas and the University of Maryland with instructors and students from both universities participating simultaneously. This synchronous learning exercise addresses more than just the logistics of multiple sites, it also allows students in two fundamentally different courses (one set from the electronic packaging community and one set from the design for environment/chemical engineering community) to interact and express their differing motivation for using the material and their differing approaches regarding solutions to similar problems.

In addition to the specific course insertions planned above, the materials developed within this effort will be made available to any other educational institution willing to provide feedback on their effectiveness. A web site will be created to allow others to access the modules, follow development plans, and provide feedback.

\section{Summary}

A new course that focuses on cost modeling for electronic systems has been developed. We propose enhancing this course by developing web-based educational modules that can be used within future cost analysis courses or as supplemental materials in other electronic packaging courses. Unique aspects of this effort include:

- Treatment of cost analysis, which has not been previously addressed in electronic packaging curricula.

- Integration of key concepts from engineering economics, life cycle costing, manufacturing cost modeling, and environmental life cycle assessment.

- Emphasis placed on the involvement with the cost modeling industry in the course.

- $\quad$ Proposed development of modules that are equally useful in cost modeling courses, or individually as supplements to exiting non-cost modeling courses.

- Interdisciplinary appeal of the modules (the modules will be initially used in Mechanical Engineering, Chemical Engineering, and business/law programs.

\section{References}

1. Wesling, P., "Models for Internet-Delivered Courses in Electronics Packaging," Proc 49 $9^{\text {th }}$ Electronic Components and Technology Conf, 1999, pp. 10511055.

2. Sandborn, P. A., and Murphy, C. F., "A Model for Optimizing the Assembly and Disassembly of Electronic Systems," IEEE Trans. on Electronics Packaging Manufacturing, Vol. 22, No. 2, (1999), pp. 105-117.

3. Joshi, Y., Bar-Cohen, A., and Bhavnani, S., "Internet Based Instruction of Thermal Design of Electronic Product - Making a Global Impact," Proc. $49^{\text {th }}$ Electronic Components and Technology Conf., 1999, pp. 1060-1064. 